University of Nebraska - Lincoln

DigitalCommons@University of Nebraska - Lincoln

USDA Wildlife Services - Staff Publications

U.S. Department of Agriculture: Animal and Plant Health Inspection Service

2021

\title{
Efficacy and risks from a modified sodium nitrite toxic bait for wild pigs
}

\author{
Nathan P. Snow \\ USDA APHIS Wildlife Services, nathan.p.snow@aphis.usda.gov \\ Jason Wishart \\ imal Control Technologies Australia Pty Ltd, Somerton, Australia, jason.wishart@invasiveanimals.com
}

Justin A. Foster

Texas Parks and Wildlife Department

Linton D. Staples

Animal Control Technologies Australia Pty Ltd

Kurt C. Vercauteren

USDA APHIS Wildlife Services, kurt.c.vercauteren@usda.gov

Follow this and additional works at: https://digitalcommons.unl.edu/icwdm_usdanwrc

Part of the Natural Resources and Conservation Commons, Natural Resources Management and

Policy Commons, Other Environmental Sciences Commons, Other Veterinary Medicine Commons,

Population Biology Commons, Terrestrial and Aquatic Ecology Commons, Veterinary Infectious Diseases

Commons, Veterinary Microbiology and Immunobiology Commons, Veterinary Preventive Medicine,

Epidemiology, and Public Health Commons, and the Zoology Commons

Snow, Nathan P.; Wishart, Jason; Foster, Justin A.; Staples, Linton D.; and Vercauteren, Kurt C., "Efficacy and risks from a modified sodium nitrite toxic bait for wild pigs" (2021). USDA Wildlife Services - Staff Publications. 2438.

https://digitalcommons.unl.edu/icwdm_usdanwrc/2438

This Article is brought to you for free and open access by the U.S. Department of Agriculture: Animal and Plant Health Inspection Service at DigitalCommons@University of Nebraska - Lincoln. It has been accepted for inclusion in USDA Wildlife Services - Staff Publications by an authorized administrator of DigitalCommons@University of Nebraska - Lincoln. 


\title{
Efficacy and risks from a modified sodium nitrite toxic bait for wild pigs
}

\author{
Nathan P Snow, ${ }^{a^{*}} \oplus$ Jason D Wishart, ${ }^{b}+{ }^{+}$Justin A Foster, ${ }^{c}$ Linton D Staples ${ }^{b}$ \\ and Kurt C VerCauteren ${ }^{\mathrm{a}}$
}

\section{Abstract}

BACKGROUND: Wild pigs (Sus scrofa) are a destructive invasive species throughout many regions of the world. In 2018, a field evaluation of an early prototype of a sodium nitrite (SN) toxic bait in the United States revealed wild pigs dropped large amounts of the toxic bait outside the pig-specific bait stations while feeding, and thus subsequent hazards for non-target animals. We modified the SN-toxic bait formulation, the design of the bait station, and the baiting strategy to reduce dropped bait. We tested the modifications in Queensland, Australia (December 2018), Alabama, USA (August 2019), and Texas, USA (March 2020) under differing climatic and seasonal conditions for one night.

RESULTS: Cumulatively we found 161 carcasses of all age classes of wild pigs using systematic transects. Remote camera indices indicated high lethality for wild pigs, achieving population reductions of 76.3 to $90.4 \%$. Wild pigs dropped only small particles of SN-toxic bait (average $=\mathbf{5 5 . 5} \mathrm{g}$ per bait site), which represented a 19-fold decrease from the previous trial. Despite this reduction, we found three Australian ravens (Corvus coronoides) in Queensland, two Virginia opossums (Didelphis virginiana) in Alabama, and 35 granivorous-passerine birds (mostly dark-eyed juncos [Junco hyemalis]) in Texas dead from consuming the dropped bait. We did not detect any population-level effects for those species.

CONCLUSION: Our modifications were effective at reducing populations of wild pigs, but the deaths of non-target species require further steps to minimize these hazards. Next steps will include evaluating various deterrent devices for birds the morning after SN-toxic bait has been offered.

Published 2020. This article is a U.S. Government work and is in the public domain in the USA

Supporting information may be found in the online version of this article.

Keywords: feral swine; integrated pest management; pesticide; registration; Sus scrofa; toxicant; wild boar; wildlife damage management

\section{INTRODUCTION}

Wild pigs (Sus scrofa), also referred to as feral hogs, feral pigs, feral swine, invasive wild pigs, or wild boars, ${ }^{1}$ are a widely distributed and destructive species throughout parts of North America, Australia, South America, Africa, and many island nations. ${ }^{2}$ In particular, populations of wild pigs have been increasing and expanding throughout the United States and Australia. ${ }^{3-5}$ Wild pigs cause extensive damage to agricultural and ecological resources, ${ }^{6-8}$ are a serious endemic and exotic disease risk, ${ }^{3}$ and are expensive to control. ${ }^{7}$ Common methods for control include trapping, snaring, recreational hunting, professional sharpshooting, and aerial shooting, ${ }^{9-11}$ although these methods are rarely successful for controlling wild pigs across large regions or landscape-scales. ${ }^{12-14}$

Toxic baits for wild pigs that are humane and safe for non-target animals are desirable because they can provide an additional option for large-scale population control of wild pigs. ${ }^{15,16}$ Currently, the only toxic bait registered for use in the United States by the US Environmental Protection Agency (EPA) contains the anticoagulant, warfarin. ${ }^{17}$ However, despite this toxic bait being federally registered in 2017, no states have allowed its use because of concerns over humaneness and hazards to non-targets. ${ }^{18}$ Until recently, only two active ingredients have been approved for use in Australia, sodium fluoroacetate (compound 1080) and yellow phosphorus, but both of these have generated similar concerns. ${ }^{16}$

A new toxic bait containing sodium nitrite (SN) has been developed for use in the United States and Australia, ${ }^{19-21}$ and was recently registered for use in Australia in 2019 by the Australian Pesticides and Veterinary Medicines Authority $\left(\mathrm{HOGGONE}^{\circledR}\right.$;

\footnotetext{
* Correspondence to: NP Snow, USDA/APHIS/Wildlife Services, National Wildlife Research Center, 4101 LaPorte Avenue, Fort Collins, CO 80521-2154, USA. E-mail: nathan.p.snow@usda.gov

+ Present address: Agriculture Victoria, 89 Sydney Road, Benalla, VIC 3672, Australia

a USDA/APHIS/Wildlife Services, National Wildlife Research Center, Fort Collins, CO, USA

b Animal Control Technologies Australia Pty Ltd, Somerton, Australia

c Texas Parks and Wildlife Department, Kerr Wildlife Management Area, Hunt, TX, USA
} 
Animal Control Technologies Australia P/L, Victoria, Australia). SN is an acute and humane toxicant ${ }^{22}$ that kills by inhibiting oxygen delivery to tissues and organs (i.e. methemoglobinemia) $<3 \mathrm{~h}$ post-ingestion. ${ }^{20} \mathrm{SN}$ is also metabolized quickly by wild pigs prior to death and does not bioaccumulate, which mitigates secondary risks to scavengers or predators of carcasses of wild pigs. ${ }^{23}$ Early developers of a SN-toxic bait suggested it was ideal for wild pigs because wild pigs lacked the level of enzymes required to counteract the methemoglobinemia. ${ }^{24,25}$ However, later investigations revealed that other mammals such as white-tailed deer (Odocoileus virginianus), ${ }^{26}$ raccoons (Procyon lotor), ${ }^{26}$ and small birds ${ }^{27}$ were also sensitive to SN if they consumed the toxic bait. Therefore, a wild pig-specific bait station ${ }^{28,29}$ and baiting strategy ${ }^{30}$ were developed to protect the $\mathrm{SN}$-toxic bait from non-target species while maximizing access by groups of wild pigs. ${ }^{21}$

After several years of field testing in Australia, the first field evaluation of a SN-toxic bait in the United States was undertaken in Texas in $2018 .{ }^{31}$ It revealed a $\sim 70 \%$ population reduction of wild pigs with only 1-2 nights of toxic baiting. However, high levels of non-target mortalities were also observed from non-target animals consuming SN-toxic bait that was dropped outside the bait station by wild pigs. An average of $1.05 \mathrm{~kg}$ (standard error $[S E]=0.6$ ) of SN-toxic bait, equivalent to $3.7 \%$ of the bait offered, was dropped outside of bait stations by wild pigs at each bait site while they were feeding on SN-toxic bait (N. P. Snow, US Department of Agriculture [USDA], unpublished data). Non-target species that succumbed to the dropped bait mostly included small granivorous birds (e.g. white-crowned sparrows [Zonotrichia leucophrys] and red-winged black birds [Agelaius phoeniceus]), and to a lesser extent raccoons and wild turkeys (Meleagris gallopavo). The non-target mortalities were suspected to have stemmed from a variety of mechanisms which led to non-targets accessing SNtoxic bait that was spilled outside of the bait stations, including: (i) the SN-toxic bait was not compacted into the bait station which may have allowed wild pigs to scoop the bait out, (ii) wild pigs may have detected the SN and dropped the bait outside of the bait station, and (iii) an extended pre-baiting period (18 days) using whole-kernel corn may have excessively attracted the non-target animals to the bait site.

The unexpected non-target mortalities led us to make modifications to the bait station, the formulation of the bait, and the baiting strategy to minimize risks to non-targets. Firstly, we revised the bait station to accept small, compacted trays of the SN-toxic bait to prevent wild pigs from scooping the bait onto the ground. Secondly, we reformulated the original SN-toxic bait in attempt to reduce the risks to non-target species. The original bait included $10 \%$ SN $w / w$ that was microencapsulated and mixed into a matrix of peanut paste bait with crushed grains. ${ }^{19,20}$ The reformulation included: (i) increasing the microencapsulation coating around the $\mathrm{SN}$ to increase palatability for wild pigs, (ii) decreasing the SN concentration by $50 \%$ (i.e. from $10 \%$ to $5 \%$ SN $w / w$ ) in an attempt to minimize the amount of SN deployed, and (iii) more finely milling the crushed grains into grain-flour to reduce the attractiveness to small granivorous birds. Thirdly, we revised the baiting strategy in attempt to reduce the attractiveness of the bait sites to non-target animals. We decreased the amount of prebaiting time with freely available whole-kernel corn by 4-6 days. We also placed the bait stations $\sim 10-30 \mathrm{~m}$ away from the original pre-baiting sites where whole-kernel corn was used to cluster wild pigs to avoid any remnant particles of whole-kernel corn that might attract granivorous birds. ${ }^{32}$ Lastly, we reduced the amount of SN toxic bait deployed in each bait station from $\sim 20$ to $\sim 7.5 \mathrm{~kg}$ to reduce the amount of SN placed on the landscape.

Our first objective was to evaluate our modifications to the SNtoxic baiting approach to determine how the modifications influenced lethality for free-ranging wild pigs. Second, we examined if the modifications reduced the amount of SN-toxic bait dropped outside the bait station by wild pigs during feeding. Third, we evaluated the reformulated bait and baiting strategy in the United States (southern Alabama and north-central Texas) with a primary goal of determining if there were any adverse effects for non-target species.

\section{MATERIALS AND METHODS}

\subsection{Study area}

The first field trial incorporating all the modifications was conducted during December 2018 in south-central Queensland, Australia (QLD 2018; Fig. 1). The temperature averaged $36.0^{\circ} \mathrm{C}$ and $9.8 \mathrm{~mm}$ of precipitation occurred during the study (https://www.bom.gov.au; Bureau of Meteorology, Australian Government). The landscape is characterized as a temperate grassland, savanna, and shrubland ecoregion. ${ }^{33}$ Vegetation is comprised primarily of poplar box (Eucalyptus populnea), silver leaved ironbark (E. melanophloia), river red gum (E. camaldulensis), coolibah (E. coolibah), yapunyah (E. ochriophoia) and Mitchell grass (Astrebla spp.).

The second field trial was conducted during August 2019 in southern Alabama, USA (AL 2019). The temperature averaged $27.6{ }^{\circ} \mathrm{C}$ and $120.9 \mathrm{~mm}$ of precipitation occurred during the study (https://www. wunderground.com/history). The landscape is characterized as part of the south-eastern plains ecoregion; a mosaic of croplands, pasturelands, and woodland forests that are predominately longleaf pine (Pinus palustris) with a mixture of oak (Quercus spp.), hickory (Carya spp.), and pine (Pinus spp.) forest. ${ }^{34,35}$

The third field trial was conducted in north-central Texas during February and March 2020 (TX 2020). The temperature averaged $5.5^{\circ} \mathrm{C}$, and $13.0 \mathrm{~mm}$ of precipitation occurred during the study (https://www.wunderground.com/history). The landscape is characterized as part of the south-western tablelands ecoregion, dominated by juniper (Juniperus spp.), scrub oak (Quercus spp.), and midgrass savanna ${ }^{34,35}$ with interspersed croplands. The Texas study area was $\sim 176 \mathrm{~km}$ west of the original 2018 SN-toxic bait field trial that occurred in February and March of 2018. We deployed the SN-toxic bait during the exact same day (i.e. March 2), for a best comparison between the 2018 and 2020 field trials in Texas to avoid any potential confounding from seasonality.

\subsection{Study design}

All field trials were conducted under nearly identical methodologies with a few exceptions described later. For the first field trial (QLD 2018), we baited and evaluated 14 independent sites primarily to assess the amount of toxic SN bait that was dropped by wild pigs outside of the wild pig-specific bait stations. We also assessed the efficacy of the SN bait on localized populations of wild pigs and identified any mortalities for non-target species. We did not include control sites (i.e. non-toxic sites) in the QLD 2018 trial because amounts of spilled bait at non-toxic sites would not be representative of toxic site. Wild pigs would succumb quickly to the SN at toxic sites, ${ }^{20}$ whereas they could forage for extended durations and consume spilled bait at non-toxic sites. For the second and third field trials (AL 2019 and TX 2020), we used a similar design except we baited and evaluated five independent toxic sites and five independent control sites, respectively. We included control sites to determine if any observed 

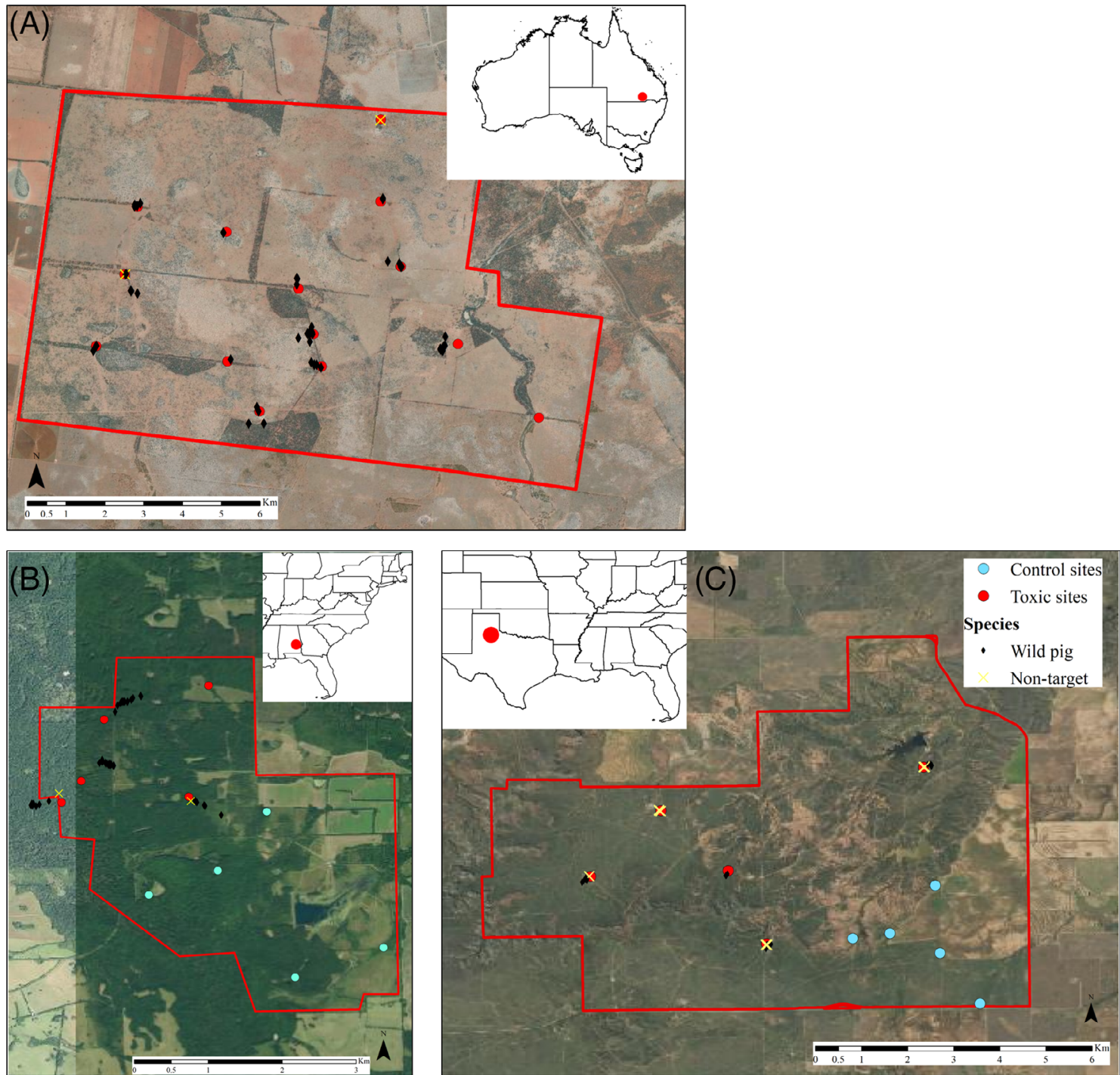

Figure 1. Study areas, bait sites, and locations of carcasses found after one night of SN-toxic baiting in (A) Queensland, Australia (December 2018), (B) Alabama, USA (August 2019), and (C) Texas, USA (March 2020).

reductions in non-target presence during post-toxic baiting was attributed to the SN-toxic bait or other factors (e.g. deterred by the wild pig-specific bait station).

For all three trials, we conducted the studies during times of year when we expected the highest success in attracting wild pigs to our bait sites. Specifically, in QLD 2018 we conducted the study during the hot and dry seasons when we expected the movements of wild pigs would be limited by water on the landscape. Similarly, in AL 2019 we also targeted the hot and dry time of year when pigs would be limited by water, but the conditions were more humid than QLD 2018. In TX 2020 we conducted the study prior to crop planting and spring green-up, when we expected food resources to be limited for wild pigs. All research methods were approved under the Queensland Government Animal Ethics Committee (CA 2018/04/118), and the USDA National Wildlife Research Center, Institutional Animal Care and Use Committee (QA-2990 and QA-3068).

\subsection{Baiting wild pigs}

Based on previous research, we followed a pre-baiting and conditioning strategy for wild pigs that took $\sim 13$ days to cluster groups of wild pigs to a bait site before ultimately deploying the SN-toxic bait (Table 1). ${ }^{21,30,36}$ We initiated pre-baiting with whole-grain wheat (i.e. QLD 2018) or whole-kernel corn (i.e. AL 2019 and TX2020) at sites with obvious pig activity (e.g. wallows, rooting, trails, etc.) for $\sim 5$ days. We initially pre-baited up to twice the number of sites than were ultimately used in the toxic phase of the trials to ensure we established enough bait sites and we selected the best bait sites for deploying the toxic bait. For selecting pre-baiting sites, we used a goal of maintaining $>500 \mathrm{~m}$ separation between bait sites, in attempt to locate discrete family groups of wild pigs. ${ }^{30,36,37}$ We deployed time lapse cameras (see later) at all sites to enable determination of the approximate numbers and uniquely identifiable characteristics (e.g. group of ten wild pigs with two nursing sows and eight piglets) of wild pigs at each site. We identified the best pre-baiting sites by ranking each of the sites and selecting the greatest ranked from: (i) consistent visitation by wild pigs (i.e. $\geq 2$ days in a row), (ii) consistent visitation by a single family group of wild pigs (i.e. one or more females with multiple juveniles or piglets), (iii) consistent visitation by more than one family group, and (iv) consistent visitation by family groups that were independent 
Table 1. Baiting strategy for locating, pre-baiting, and training wild pigs to use bait stations and consume a sodium nitrite (SN)-toxic bait used in Queensland, Australia (December 2018), Alabama, USA (August 2019), and Texas, USA (March 2020)

Amount of bait deployed at each site daily $(\mathrm{kg})$

\begin{tabular}{|c|c|c|c|c|}
\hline Nights of study ${ }^{a}$ & Study activity & Whole-grain & Placebo bait & SN-toxic bait \\
\hline $1-5$ & Pre-baiting on ground - locate wild pigs & $\sim 10$ & 0.0 & 0 \\
\hline $6-7$ & Training $^{\mathrm{b}}$ - introduce bait stations, lids propped $25 \mathrm{~cm}$ & 7.5 & 0.0 & 0 \\
\hline 8 & Training - bait station lids propped $5 \mathrm{~cm}$ & 7.5 & 2.5 & 0 \\
\hline $9-10$ & Pre-Placebo baiting - bait station lids closed with $13 \mathrm{~kg}$ magnetic resistance & 0 & 7.5 & 0 \\
\hline $11^{\mathrm{c}}$ & Toxic baiting - bait station lids closed with $13 \mathrm{~kg}$ magnetic resistance & 0 & 0 & 7.5 \\
\hline $12-13$ & Post-Placebo baiting - bait station lids closed with $13 \mathrm{~kg}$ magnetic resistance & 0 & 7.5 & 0 \\
\hline \multicolumn{5}{|c|}{$\begin{array}{l}\text { a Nights were adjusted } \pm 2 \text { days at any stage to account for wild pigs that did not visit during certain nights, that could not access and needed a longer } \\
\text { training period, or that readily accessed and needed a shorter training period. Emphasis was placed on moving through the training periods as quickly } \\
\text { as possible while allowing the majority of wild pigs to access bait stations at each stage, based on examination of remote camera images each day } \\
\text { b Bait stations were placed } 10-30 \text { m from where pre-baiting occurred on the ground to avoid any particles of grain left on the ground. } \\
{ }^{c} \text { Control bait sites received placebo bait in lieu of SN-toxic bait. }\end{array}$} \\
\hline
\end{tabular}

from any family groups observed at other bait sites. Our goal was to have independent family groups visiting each of the final bait sites. We did not select sites based on non-target presence or abundance to best represent realistic baiting scenarios (i.e. focus on targeting wild pigs).

Once the best sites were selected, we deployed the bait stations and initiated the conditioning phases for training wild pigs to access the bait stations (Table 1). The bait stations were backto-back troughs with hinged lids that were locked closed with $13 \mathrm{~kg}$ of magnetic pressure. ${ }^{28,29}$ For sites with an estimated greater than ten wild pigs, we deployed two bait stations to ensure all animals had access to the bait simultaneously. In AL 2019 and TX 2020, the bait stations were deployed 10-30 m away from the original pre-baiting site to avoid any remnant particles of grain that were possibly attractive to non-target animals. In QLD 2018 and TX 2020, we constructed three-strand barbed wire fences surrounding the bait stations $(\sim 10 \mathrm{~m}$ $\times 10 \mathrm{~m}$ ) to exclude cattle that were grazing in the area from the $\mathrm{SN}$-toxic bait.

We weighed the placebo bait pre- and post-SN-toxic baiting to evaluate for changes in consumption related to toxic baiting. Also, in QLD 2018 we carefully searched for, collected and weighed any SN-toxic bait that was dropped outside of the bait station by wild pigs. In AL 2019 and TX 2020 we did not collect any dropped SNtoxic bait in order to evaluate worst-case non-target impacts in a field setting.

\subsection{Systematic transects}

The morning following deployment of SN-toxic bait, we searched systematic transects surrounding bait sites to locate any dead wild pigs or non-target animals. Specifically, in QLD 2018 we searched $600 \mathrm{~m}$ transects, separated by $50 \mathrm{~m}$, within a $600 \mathrm{~m}$ $\times 600 \mathrm{~m}$ square centered on bait sites. In AL 2019 and TX 2020, we searched $400 \mathrm{~m}$ transects, separated by $20 \mathrm{~m}$, within a $400 \mathrm{~m} \times 400 \mathrm{~m}$ square centered on bait sites. We reduced the spacing between transects in AL 2019 and TX 2020 to facilitate detection of any small non-target animals that might have been overlooked from farther distances (e.g. small birds). Also, in AL 2019 and TX 2020 we searched the transects for three consecutive days following the single night of SN-toxic baiting, to locate any animals that may have died from consuming dropped bait after a longer period.
Once a dead wild pig was located, we recorded the sex, age from tooth eruption, ${ }^{38}$ weight (in kilograms), and global positioning system (GPS) location. Evidence of SN-toxic bait consumption was assessed by visual inspection of a drop of blood on a white laminated card, and compared the darkness of the blood to a standard curve representing the percentage of methemoglobin ${ }^{39}$ as a measure of SN toxicosis. For any non-targets located, we recorded species, sex (if identifiable), location, and evidence of SN toxicity as described earlier.

\subsection{Remote camera monitoring}

We placed two remote cameras on each bait site. Both cameras were mounted $5 \mathrm{~m}$ from the bait, $1.5 \mathrm{~m}$ above the ground on a T-post or tree, and angled down at $\sim 70^{\circ}$ to standardize the field of view. The first camera was set to record one time-lapse image of the bait site every 5 min thus recording 288 images per day. The time-lapse imagery was used to calculate hourly indices of visitation by all species. The second camera was set to record motion-activated images at bursts of three images separated by $5 \mathrm{~s}$ intervals, with a $5 \mathrm{~s}$ delay between motion-activated bursts. The motion activated cameras were used to assess behaviors of animals at the bait sites (i.e. consuming bait, accessing the bait station, etc.).

We viewed the camera imagery daily to inform the requirements described earlier for selecting the best bait sites and monitoring how wild pigs progressed through the conditioning phases. For examining changes in populations of animals related to the toxic bait, we focused specifically on the $24-\mathrm{h}$ periods preand post-SN-toxic baiting to ensure the changes in population were related to the toxic bait and not other factors that may influence visitation to bait sites (e.g. changing environmental or climatic conditions). Images from time-lapse cameras during the 24-h period pre- and post-toxic baiting were imported and scored using the Colorado Parks and Wildlife Photo Database for image processing. ${ }^{40} \mathrm{~A}$ single-observer technique was used to identify and count the number of species in each image. We calculated the hourly rate of visitation for each species as the total count observed during each period (i.e. summed across all the 5-min time-lapse images for each period) divided by the number of hours monitored during each period (i.e. $\sim 24 \mathrm{~h}$ ).

For each study location, we grouped non-target animals into non-target mammals and granivorous birds. We used these 
specific groups for analysis because they were the most susceptible to SN-toxic bait in the previous 2018 field evaluation ${ }^{31}$ and they included $\sim 90 \%$ of all non-target animals that were observed at bait sites in this study. Our grouping of granivorous birds included omnivorous birds that are known to eat grains (e.g. Corvus spp.). In QLD 2018 we excluded emus (Dromaius novaehollandiae) from analysis because we only had one bait site where emus were observed, they did not appear interested in the placebo or SN-toxic bait, but they were in the field of view of one camera for many hours and therefore skewed the counts of daily visitation. We did not include predatory birds because their presence was sporadic and dependent on the other species of nontargets visiting our bait sites. We also did not include cattle because we used fences to exclude them from the bait sites. Finally, we did not include amphibians because their presence was dependent on rain (i.e. only observed after rainfall in AL 2019).

\subsection{Data analysis}

For the systematic transects, we calculated descriptive summaries of sexes, ages, and distances from carcass to nearest bait station for wild pigs that succumbed to the SN-toxic bait. We also summarized any non-target deaths and distances from the nearest bait site. We compared consumption of placebo bait pre- and post-SN-toxic bait deployment using a generalized mixed model in Program $\mathrm{R}$ (version 3.6.3, The R Foundation for Statistical Computing, Vienna, Austria). We treated Site identification (ID) as a random effect to account for repeated measures at each site. For all analyses we calculated and examined the $95 \%$ confidence intervals (Cls) surrounding the regression coefficients $(\beta)$ for non-overlap of zero to indicate statistical and biological differences.

From the time-lapse imagery, we used the hourly rates of visitation to the bait sites as indices of the baited populations pre- and post-toxic baiting, to make inferences to changes in population abundances relative to one night of toxic baiting. We expect we met the important assumption that the probability of detecting animals remained consistent ${ }^{41}$ at the bait sites because we refreshed the bait every day and the 24-h periods of indexing were only separated by a single $24-\mathrm{h}$ period when the toxic bait was deployed. Specifically, we compared the hourly rates of visitation by wild pigs during the $24-\mathrm{h}$ periods pre- and post-SN-toxic baiting using a negative binomial generalized mixed model with package glmmTMB. ${ }^{42}$ For AL 2019 and TX 2020, we also included an interaction term for night (pre- versus post-SN-toxic bait) $\times$ treatment (i.e. SN-toxic bait versus control) to evaluate for differences between treatment and control sites related to SN-toxic bait. We used Site ID as a random effect as described earlier. We conducted the same analyses for non-target mammals and granivorous birds to examine for potential declines in their local populations from the SN-toxic bait. Post hoc, we analyzed for declines in dark-eyed juncos (Junco hyemalis) from TX 2020.

\section{RESULTS}

Overall, wild pigs were the most frequently observed species visiting the bait sites in all study areas, however $\geq 38$ non-target species were also observed within 1-2 days pre- and post-SN-toxic bait deployment (Supporting Information, Table S1). We observed 6479 time-lapse images with wild pigs and 5309 images with nontarget species, equating to non-targets being present at the bait sites $82 \%$ as much as wild pigs. Cumulatively, we located the carcasses of 161 wild pigs and 40 non-target animals (from five different species) following one night of SN-toxic baiting at all 24 bait sites (Table 2; Fig. 1). Thirty-eight of the 40 (95\%) non-target animals were granivorous or omnivorous birds, and 35 of those were found in the TX 2020 study area. The non-target birds were found within a few meters of the bait sites (range $=3.1-36.5 \mathrm{~m}$ ), usually under adjacent trees and shrubs. Whereas, wild pigs were found an overall average of $208 \mathrm{~m}$ away. All of the carcasses found showed evidence of SN toxicity except for one Virginia opossum (Didelphis virginiana) in AL 2019 which was not confirmed to have been killed by SN because the carcass was too decomposed to

Table 2. Counts and distances of carcasses found after one night of sodium nitrite (SN)-toxic baiting in Queensland (QLD), Australia (December 2018), Alabama (AL), USA (August 2019), and Texas (TX), USA (March 2020)

\begin{tabular}{|c|c|c|c|c|c|c|c|}
\hline \multirow[b]{3}{*}{ Location } & \multirow{3}{*}{$\begin{array}{l}\text { Number } \\
\text { of SN- } \\
\text { toxic bait } \\
\text { sites }\end{array}$} & \multicolumn{4}{|c|}{ Wild pigs } & \multicolumn{2}{|l|}{ Non-target species } \\
\hline & & \multirow{2}{*}{$\begin{array}{l}\text { Number of } \\
\text { carcasses located } \\
\text { (male, female, }^{\text {unknown })^{\mathrm{a}}}\end{array}$} & \multirow{2}{*}{$\begin{array}{l}\text { Distance }(\mathrm{m}) \\
\text { from nearest } \\
\text { bait site }(\mathrm{SE})\end{array}$} & \multicolumn{2}{|c|}{$\begin{array}{c}\text { Average } \\
\text { difference in } \\
\text { consumption } \\
\text { pre-/post-toxic } \\
\text { baiting } \\
\text { (proportion) }\end{array}$} & \multirow[b]{2}{*}{ Number of non-target carcasses } & \multirow{2}{*}{$\begin{array}{l}\text { Distance }(\mathrm{m}) \\
\text { from nearest } \\
\text { bait site }(\mathrm{SE})\end{array}$} \\
\hline & & & & $\begin{array}{l}\text { Toxic } \\
\text { sites }\end{array}$ & $\begin{array}{l}\text { Control } \\
\text { sites }\end{array}$ & & \\
\hline $\begin{array}{l}\text { QLD, } \\
\text { Australia }\end{array}$ & 14 & $68(41,27,0)$ & $186.3(18.2)$ & -0.65 & NA & $\begin{array}{c}3- \\
\text { Australian raven (Corvus coronoides) }\end{array}$ & $12.3(1.1)$ \\
\hline AL, USA & 5 & $53(23,28,2)$ & $341.8(13.0)$ & -0.59 & 0.18 & 2 - Virginia opossum (Didelphis virginiana) & $94.7(23.5)$ \\
\hline TX, USA & 5 & $40(19,21,0)$ & $96.4(6.5)$ & -0.65 & 0.00 & $\begin{array}{c}28 \text { - Dark-eyed junco (Junco hyemalis); } 5 \text { - } \\
\text { white-crowned sparrow (Zonotrichia } \\
\text { leucophrys); } 2 \text { - chipping sparrow (Spizella } \\
\text { passerina) }\end{array}$ & $18.4(1.6)$ \\
\hline
\end{tabular}




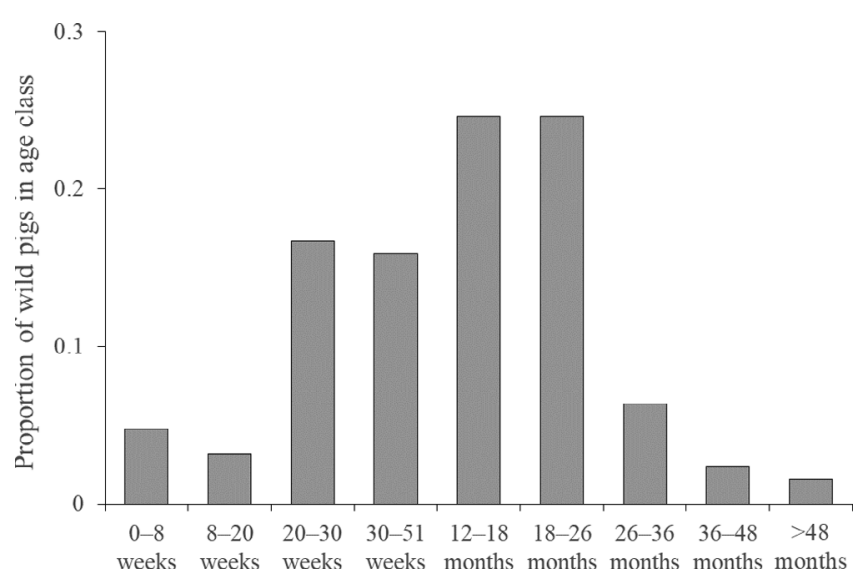

Figure 2. Cumulative proportions of age classes of wild pig carcasses found after one night of SN-toxic baiting in Queensland, Australia (December 2018), Alabama, USA (August 2019), and Texas, USA (March 2020).

extract a usable sample of blood. Overall, we located 22.6, 26.5, and 1.1 carcasses of wild pigs for every carcass of a non-target species that we found in QLD 2018, AL 2019, and TX 2020, respectively.

Overall, we offered $417.9 \mathrm{~kg}$ of SN-toxic bait, and consumption averaged $53 \%$ (range $=10-95 \%$ ) from each bait site, indicating the bait was highly palatable despite being acute-acting. All age classes of wild pigs were susceptible to the SN-toxic bait (Fig. 2). Consumption of placebo bait at the toxic bait sites declined by $59-65 \%$ following one night of SN-toxic baiting ( $\beta=-0.55 ; 95 \%$ $\mathrm{Cl}=-0.70$ to -0.39 ), indicating substantial lethality to wild pigs (Table 2, Fig. 3). Whereas, consumption of placebo stayed the same at control sites in AL 2019 and TX 2020 ( $\beta=0.08 ; 95 \%$ $\mathrm{Cl}=-0.09$ to 0.25 ). Additionally, we found an average of $55.5 \mathrm{~g}$ $(\mathrm{SE}=10.3)$ of dropped SN-toxic bait outside of the bait stations in QLD 2018. Despite 3 days of searching for carcasses in AL
2019 and TX 2020, all of the non-target carcasses were found on the first day (i.e. morning following SN-toxic bait deployment), suggesting risks to non-target species from dropped bait were brief.

From remote cameras in QLD 2018, we found a significant reduction in visitation by wild pigs during the post-SN-toxic baiting night ( $\beta=-2.34 ; 95 \% \mathrm{Cl}=-3.31$ to -1.38 ), averaging a $90.4 \%$ decline in the baited population of wild pigs. Similarly, the interaction of night $\times$ treatment showed a substantial decrease in wild pig visitation during the post-SN toxic night than observed at control sites in AL 2019 ( $\beta=-2.52 ; 95 \% \mathrm{Cl}=-4.24$ to -0.81 ; Fig. 4) and TX 2020 ( $\beta=-2.14 ; 95 \% \mathrm{Cl}=-3.22$ to -1.05$)$. We found average declines of $76.3 \%$ and $81.6 \%$ in hourly visitations by wild pigs following one night of SN-toxic baiting in AL 2019 and TX 2020, respectively.

Also from remote cameras, we found no evidence of a decline in non-target mammals ( $\beta=3.23 ; 95 \% \mathrm{Cl}=-0.17$ to 6.63 ) or birds ( $\beta=0.49 ; 95 \% \mathrm{Cl}=-0.12$ to 1.09 ) at bait sites following $\mathrm{SN}$-toxic baiting in QLD 2018. In AL 2019, we found an increase in the number of non-target mammal visits per hour $(\beta=1.64 ; 95 \%$ $\mathrm{Cl}=0.04$ to 3.24$)$ and no change in the number of bird visits per hour ( $\beta=0.72 ; 95 \% \mathrm{Cl}=-1.98$ to 3.42 ) following SN-toxic baiting. Finally in TX 2020, despite the 35 non-target mortalities we found no change in visits per hour by non-target mammals ( $\beta=0.11 ; 95 \% \mathrm{Cl}=-3.63$ to 3.84$)$ or birds $(\beta=-1.23 ; 95 \%$ $\mathrm{Cl}=-3.03$ to 0.57 ) following $\mathrm{SN}$-toxic baiting. Similarly, the post hoc analysis revealed that despite identifying 28 mortalities of dark-eyed juncos (i.e. the greatest of any non-target species), we did not observe evidence of local population declines for that particular species at toxic bait sites $(\beta=-1.32 ; 95 \% \mathrm{Cl}=-3.95$ to 1.32 ).

\section{DISCUSSION}

Our results from three distinct regions covering a range of climatic and landscape conditions, indicated that the recently reformulated SN-toxic bait, and modified bait station and baiting strategy,

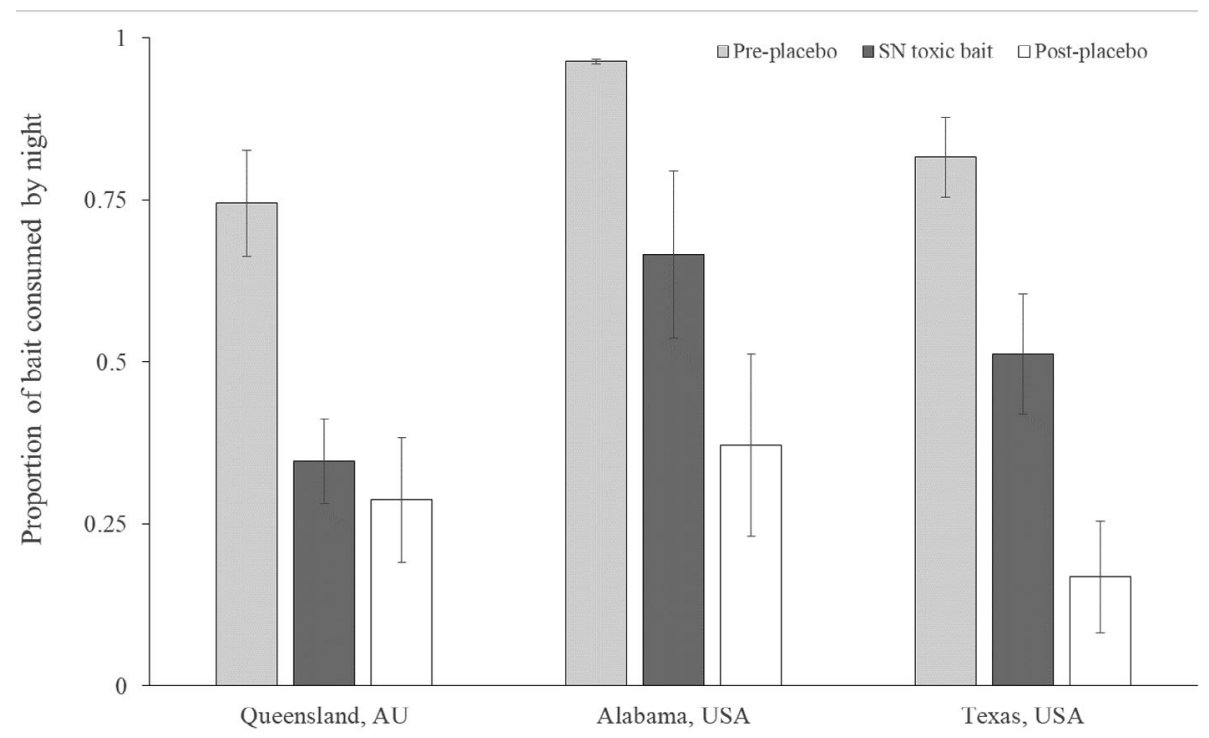

Figure 3. Average consumption recorded for two nights of placebo bait pre- and post-deployment of one night of SN-toxic bait inside bait stations in Queensland, Australia (December 2018), Alabama, USA (August 2019), and Texas, USA (March 2020). Placebo bait was identical to the SN-toxic bait except without the SN. Error bars are standard errors. 

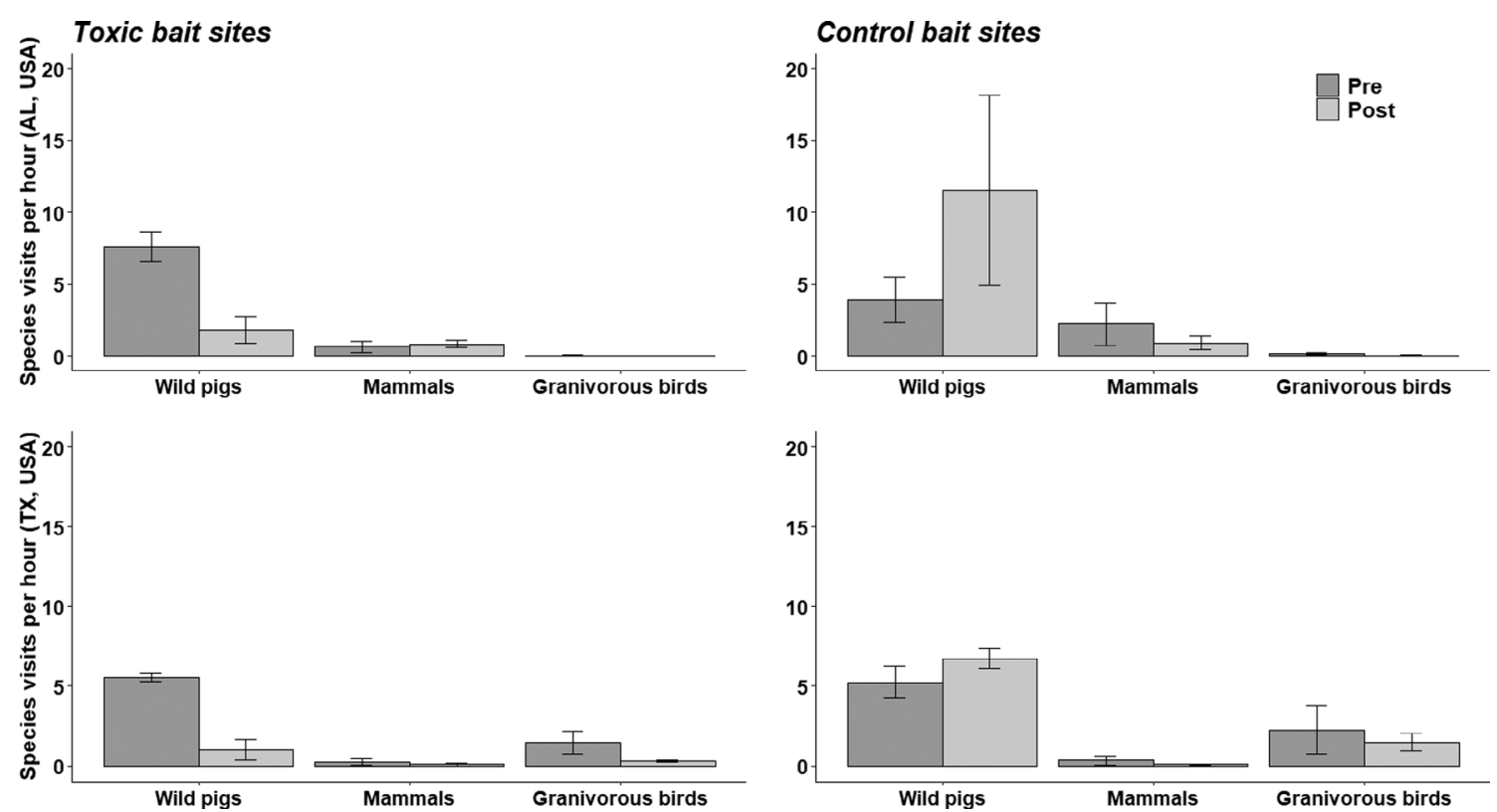

Figure 4. Indices of visitation to bait sites pre- and post-deployment of one night of SN-toxic bait in Alabama, USA (August 2019), and Texas, USA (March 2020). Control sites were treated identically to the toxic sites except only placebo bait was offered. Placebo bait was identical to the $\mathrm{SN}$-toxic bait except without the SN. Error bars are standard errors.

were highly effective at removing wild pigs with just one night of SN-toxic baiting (efficacy $=76.3-90.4 \%$ ). Considering that some surviving wild pigs returned after one night of SN-toxic baiting and consumed placebo bait, we expect that following up with more nights of SN-toxic baiting would likely increase the number of wild pigs removed. However, even with just one night, the reformulated SN-toxic bait was similarly as effective as other toxic baits for wild pigs that are typically offered for multiple nights. For comparison, in 2018 the original formulation of the SN-toxic bait had an efficacy of $\sim 70 \%$ in 1-2 nights of toxic baiting for freeranging wild pigs in Texas, USA, ${ }^{31}$ and a similar formulation had an efficacy of $92 \%$ inside a $0.1 \mathrm{~km}^{2}$ pen in New Zealand in three nights of toxic baiting. ${ }^{43}$ Similarly, a field trial in Queensland, Australia with toxic baits containing $72 \mathrm{mg}$ of sodium fluoroacetate found that $86 \%$ of wild pigs were removed in 3-4 days of toxic baiting. ${ }^{44}$ Attempts to control pigs with warfarin based baits have shown more variable field efficacy (0-100\%). ${ }^{45,46}$

This study also demonstrated that the reformulated SN-toxic bait was highly palatable for wild pigs. We found that wild pigs consumed $53 \%$ (of $417.9 \mathrm{~kg}$ ) of the reformulated SN-toxic bait we offered in one night of toxic baiting, which is considerable given that $\mathrm{SN}$ is a fast-acting toxicant and wild pigs become intoxicated quickly and die before they are able to consume all the available bait. Wild pigs consumed more of the reformulated $\mathrm{SN}$-toxic bait than the original formulation tested in $2018,{ }^{31}$ however this could be a result of the original formulation containing twice the amount of SN $(10 \% \mathrm{w} / \mathrm{w})$ and wild pigs becoming intoxicated quicker. Regardless, our results indicate that fine-tuning the amount of SN toxic bait offered to wild pigs is possible to ensure no more than necessary is deployed. However, the amount we offered was not excessive and it was important to deploy enough SN toxic bait that all wild pigs could consume a lethal dose. Another study offered much less of a $10 \%$ SN-toxic bait $(6.75 \mathrm{~kg})$ for wild pigs inside a pen, and found that $96 \%$ of the bait was consumed in one night. ${ }^{43}$ For comparison with another toxic bait containing $0.005 \%$ warfarin in Texas, USA, a similar amount of warfarin toxic bait $(418.0 \mathrm{~kg})$ was deployed as was $\mathrm{SN}$-toxic bait in this study, and $36 \%$ was consumed in 4 weeks by free-ranging wild pigs. $^{45}$

The results from this study confirm previous reports that the bait station used to protect SN-toxic bait allowed reliable feeding by wild pigs. $^{21,28,30}$ In particular, we found all age classes of wild pigs accessed and succumbed to the SN-toxic bait, likely because the bait station allowed entire groups of wild pigs to feed simultaneously, with some remote cameras images frequently showing $\geq 12$ wild pigs feeding simultaneously from a single bait station. Also, the bait station incorporated a lightweight lid that smaller wild pigs could manage once a larger wild pig released the $\sim 13 \mathrm{~kg}$ of magnetic pressure. ${ }^{28,29}$ Whereas, another type of bait station designed to allow access by $1-2$ wild pigs at a time, and with $\sim 8 \mathrm{~kg}$ weighted guillotine doors, reduced feeding by $66 \%{ }^{47}$

The reformulated SN-toxic bait was fast acting for wild pigs. We found carcasses of wild pigs an average of $208 \mathrm{~m}$ from bait sites the morning following toxic baiting. However, we expect that we did not find all the carcasses of wild pigs because some carcasses were outside of our transect grids and some wild pigs were never seen on camera again following toxic baiting, but their carcasses could not be located. Previous research indicated that death from SN-toxic bait occurred $1.5-3 \mathrm{~h}$ after feeding. ${ }^{20}$ Similarly, another study with SN-toxic bait found wild pigs an average of $148 \mathrm{~m}$ from bait stations inside a large pen in New Zealand. ${ }^{43}$ Wild pigs killed with sodium fluoroacetate reportedly died an average of 232 to $283 \mathrm{~m}$ from bait sites ${ }^{44,48}$ with variable times to death (e.g. $\sim 3-80$ h). ${ }^{44,49,50}$ Wild pigs killed with a warfarin toxic bait averaged $919 \mathrm{~m}$ from bait sites ${ }^{51}$ and time to death was 7.59.5 days after initial feeding. ${ }^{52}$

Our modifications to the $\mathrm{SN}$-toxic baiting approach reduced the amount of bait dropped outside of the bait station by 19-fold, when compared to the TX 2018 trial. Nevertheless, we observed mortalities from non-target species at all study sites, and 
particularly at the TX 2020 site. These hazards existed because of three primary factors: (i) non-target species were observed at bait sites only $18 \%$ less frequently than wild pigs, (ii) wild pigs produced crumbs of SN-toxic bait outside the bait stations while they were feeding which inadvertently exposed non-target species to $\mathrm{SN}$, and (iii) small particles of SN-toxic bait dropped outside of the bait stations contained sufficient SN to be hazardous particularly for small passerine birds. Hazards for non-targets were lower in QLD 2018 and AL 2019 because flocks of small passerine birds were not present during the trials. Whereas, during March in the grasslands of northern Texas, flocks of small passerine birds were staged for migration as the spring season approached. These birds were attracted to our bait sites likely to consume small particles of dropped whole-kernel corn and placebo bait ${ }^{53-55}$ during the days it took to condition wild pigs to access the bait stations. The birds could have also been attracted to the bait sites because wild pigs disturbed the soil which may have increased invertebrate and seed availability. ${ }^{56,57}$ Regardless of the reason, our findings indicate that strategies are needed to prevent non-target species and particularly small passerine birds from accessing SNtoxic bait that is dropped by wild pigs while feeding.

Though multiple non-target mortalities were observed in two of the three trials, we did not detect a reduction in the indices of population abundance for non-targets visiting the bait sites, indicating that $\mathrm{SN}$-toxic baiting did not have population-level effects to non-target species. This was even the case for dark-eyed juncos, which were the most frequently observed non-target mortalities in TX 2020 (i.e. 28 mortalities at the five toxic bait sites). These results indicate a substantial improvement over the original formulation of SN toxic bait in which reductions of non-target birds and mammals averaged $70 \%$ at the bait sites post-toxic baiting. ${ }^{58}$ Also, non-targets appeared susceptible to the dropped bait for only a few hours, because we found their carcasses the morning following SN-toxic baiting and did not find additional carcasses during our searches the following two days. We expect we found a majority of the non-target species that were killed during toxic baiting, because SN is fast-acting and most non-targets that consumed bait did not move far from the bait sites. We also did not find evidence of dead non-targets being scavenged prior to our arrival (e.g. piles of feathers or partially consumed birds), albeit this possibly could have occurred. Comparatively, after 4 weeks of offering $0.005 \%$ warfarin toxic baits for wild pigs, researchers observed $92 \%$ reductions in visitations by non-target species which were attributed to a loss of interest by the non-target species. ${ }^{45}$ We did not observe a loss of interest by non-target species possibly because our baiting approach was shorter (13 days compared to 61 days). Finally, small burrowing rodents may have been hard to detect with our remote cameras or systematic transects, therefore further research on the potential impacts to these species is needed.

\section{CONCLUSIONS}

Our modified baiting strategy including a redesigned bait station, reformulated SN-toxic bait, and shortened baiting strategy was effective for reducing populations of wild pigs in a fast and humane manner. This bait has potential as a new tool for controlling populations of wild pigs if non-target risks can be minimized. Risks to non-target animals were minimal in two of the three study sites, but were highest in areas where flocks of small passerine birds were attracted to bait sites and wild pigs dropped small particles of SN-toxic bait outside of bait stations.
Strategies for reducing the risks could include only using SNtoxic bait at times of year when flocks of small passerine birds are not present, in locations where flocks of small passerine birds are not present, or by using deterrents for non-target species (e.g. bird scaring devices) during the short window of time after wild pigs consume the toxic bait and applicators can arrive to remove any dropped bait. Testing of these mitigation strategies will be the next steps in development of a SN toxic bait for wild pigs in the United States.

\section{ACKNOWLEDGEMENTS}

The research was supported by the US Department of Agriculture. The findings and conclusions in this publication are those of the authors and should not be construed to represent any official US Government determination or policy. Mention of commercial products or companies does not represent an endorsement by the US Government. The authors thank K. Cadell, B. Campbell, K. Causey, P. Hollis, J. Scriven, F. Thomas and V. Wiegand for access to private property. The authors thank F. Boyd, L. Fuston, K. Gruver, J. Harrison, D. Johnson, B. Leland, J. Scriven, and L. Stephens for assisting with study logistics. The authors thank L. Clontz, J. Fischer, M. Glow, J. Halseth, J. Harrison, D. Johnson, J. Kinsey, C. Kohler, M. Lavelle, K. Long, J. Marsh, D. Marshall, I. Messer, R. Reitz, C. Richardson, J. Scriven, H. Sterling, E. VanNatta, M. Walker, P. Ward, and J. Warren for assisting with data collection. The authors also thank the anonymous reviewers for their comments on this manuscript.

\section{CONFLICT OF INTEREST DECLARATION}

LDS and JDW were affiliated with the toxic bait manufacturing company and assisted with field logistics for the Australia portion of the study, and provided bait for all portions of the study. These co-authors did not contribute to the data analysis and interpretation or results. There are no other conflicts of interest from the other co-authors.

\section{SUPPORTING INFORMATION}

Supporting information may be found in the online version of this article.

\section{REFERENCES}

1 Keiter DA, Mayer JJ and Beasley JC, What is in a "common" name? A call for consistent terminology for nonnative Sus scrofa. WildI Soc Bull 40: 384-387 (2016).

2 Barrios-Garcia MN and Ballari SA, Impact of wild boar (Sus scrofa) in its introduced and native range: a review. Biol Invasions 14:2283-2300 (2012).

3 Bevins SN, Pedersen K, Lutman MW, Gidlewski T and Deliberto TJ, Consequences associated with the recent range expansion of nonnative feral swine. Bioscience 64:291-299 (2014).

4 Snow NP, Jarzyna MA and VerCauteren KC, Interpreting and predicting the spread of invasive wild pigs. J Appl Ecol 54:2022-2032 (2017).

5 West P, Assessing Invasive Animals in Australia 2008. National Land \& Water Resources Audit, Canberra, Australia (2008) Available: www. nlwra.gov.au [23 May 2016].

6 Hone J, Spatial and temporal aspects of vertebrate pest damage with emphasis on feral pigs. J Appl Ecol. 32: 311-319 (1995).

7 Pimentel D, Environmental and economic costs of vertebrate species invasions into the United States, in Managing Vertebrate Invasive Species: Proceedings of an International Symposium, ed. by Witmer GW, Pitt WC and Fagerston KA. US Department of 
Agriculture, Animal and Plant Health Inspection Service, Wildlife Services, National Wildlife Research Center, Fort Collins, CO, pp. 2-8 (2007).

8 Anderson A, Slootmaker C, Harper E, Holderieath J and Shwiff SA, Economic estimates of feral swine damage and control in 11 US states. Crop Prot 89:89-94 (2016).

9 Coblentz B and Baber D, Biology and control of feral pigs on Isla Santiago, Galapagos, Ecuador. J Appl Ecol 24:403-418 (1987).

10 Choquenot D, Kilgour RJ and Lukins BS, An evaluation of feral pig trapping. Wildl Res 20:15-21 (1993).

11 Mayer J and Brisbin IL, Wild Pigs: Biology, Damage, Control Techniques and Management. Savannah River National Laboratory, Aiken, SC, p. 400 (2009)

12 Dickson JG, Mayer JJ and Dickson JD, Wild hogs, in Wildlife of Southern Forests: Habitat and Management, ed. by Dickson JG. Hancock House Publishers, Blaine, WA, pp. 191-208 (2001).

13 Beasley JC, Ditchkoff SS, Mayer JJ, Smith MD and Vercauteren KC, Research priorities for managing invasive wild pigs in North America. J Wildl Manage 82:674-681 (2018).

14 Adams CE, Lindsey KJ and Ash SJ, Urban Wildlife Management. CRC Press, Boca Raton, FL (2006).

15 O'Brien PH, Kleba RE, Beck JA and Baker PJ, Vomiting by feral pigs after 1080 intoxication: nontarget hazard and influence of anti-emetics. Wildl Soc Bull 14:425-432 (1986).

16 Cowled BD, Elsworth P and Lapidge SJ, Additional toxins for feral pig (Sus scrofa) control: identifying and testing Achilles' heels. Wildl Res 35:651-662 (2008).

17 Franckwoiak GA, Clark T, Polyakova L and Tseveenjav B, Kaput ${ }^{\oplus}$ Feral Hog Bait containing $0.005 \%$ warfarin: an overview of its usefulness against feral hogs and safety to wildlife and humans, in Proceedings of the 18th Wildlife Damage Management Conference, ed. by Armstrong JB and Gallagher GR, Mississippi State University, Starkville, MS, USA, pp. 78-90 (2019).

18 Blake J, NECIS Sends Letter to EPA on Kaput Feral Hog Bait. The Wildlife Society (2017). Available: https://wildlife.org/necis-sends-letter-toepa-on-kaput-feral-hog-bait/ [17 March 2020].

19 Snow NP, Halseth JM, Lavelle MJ, Hanson TE, Blass CR, Foster JA et al., Bait preference of free-ranging feral swine for delivery of a novel toxicant. PLoS One 11:e0146712 (2016).

20 Snow NP, Foster JA, Kinsey JC, Humphrys ST, Staples LD, Hewitt DG et al., Development of toxic bait to control invasive wild pigs and reduce damage. Wildl Soc Bull 41:256-263 (2017).

21 Snow NP, Lavelle MJ, Halseth JM, Glow MP, VanNatta EH, Davis AJ et al., Exposure of a population of invasive wild pigs to simulated toxic bait containing biomarker: implications for population reduction. Pest Manag Sci 75:1140-1149 (2019).

22 Institute of Medical and Veterinary Science, Assessing the humaneness and efficacy of a new feral pig bait in domestic pigs. Report for the Australian Government Department of the Environment, Water, Heritage and the Arts. Canberra, Australia (2010). Available: http://www. environment.gov.au/system/files/resources/091b0583-f35c-40b3a530-f2e0c307a20c/files/pigs-imvs-report.pdf [9 May 2016].

23 Snow NP, Foster JA, VanNatta EH, Horak KE, Humphrys ST, Staples LD et al., Potential secondary poisoning risks to non-targets from a sodium nitrite toxic bait for invasive wild pigs. Pest Manag Sci 74: 181-188 (2018).

24 Lapidge S, Wishart J, Staples L, Fagerstone K, Campbell T and Eisemann J, Development of a feral swine toxic bait (Hog-Gone ${ }^{\circledast}$ ) and bait hopper (Hog-Hopper ${ }^{T M}$ ) in Australia and the USA. Proceedings of the 14th Wildlife Damage Management Conference, (2012).

25 Lapidge SJ and Eason CT, Pharmacokinetics and Methaemoglobin Reductase Activity as Determinants of Species Susceptibility and NonTarget Risks from Sodium Nitrite Manufactured Feral Pig Baits. Invasive Animals Cooperative Research Centre, Canberra (2010).

26 Foster JA, Effects of sodium nitrite on feral swine and non-targets, in Unpublished Final Report, TDA Project No FH-10-05 Texas Department of Agriculture Performance Report. Texas Department of Agriculture, Austin, TX, p. 11 (2011).

27 Stanfield K, Sodium nitrite: zebra finch (Taeniopygia guttata) oral acute toxicity test, in Unpublished report USDA National Wildlife Research Center Study No QA-3025 Smithers Viscient, Study No 137774109 EPA MRID No 50784102. USDA National Wildlife Center, Fort Collins, CO, p. 122 (2019).

28 Lavelle MJ, Snow NP, Halseth JM, Kinsey JC, Foster JA and VerCauteren KC, Development and evaluation of a bait station for selectively dispensing bait to invasive wild pigs. Wildl Soc Bull $\mathbf{4 2}$ : 102-110 (2018).

29 Snow NP, Lavelle MJ, Halseth JM, Blass CR, Foster JA and VerCauteren KC, Strength testing of raccoons and invasive wild pigs for a species-specific bait station. Wildl Soc Bull 41:264-270 (2017).

30 Lavelle MJ, Snow NP, Halseth JM, VanNatta EH, Sanders HN and VerCauteren KC, Evaluation of movement behaviors to inform toxic baiting strategies for invasive wild pigs (Sus scrofa). Pest Manag Sci 74:2504-2510 (2018).

31 United States Department of Agriculture, APHIS Wildlife Services Conducts First Field Trial of Feral Swine Toxic Bait; Plans Modifications to Mitigate Hazards to Non-Target Species (2018). Available: https://www.aphis.usda.gov/aphis/newsroom/stakeholderinfo/SA_By_Date/SA-2018/SA-06/feral-swine-bait-trial [29 July 2019].

32 Snow NP, Halseth JM, Glow MP, Lavelle MJ, Fischer JW, VanNatta EH et al., Daily and landscape influences of species visitation to toxic bait sites for wild pigs. Wildl Soc Bull (in press).

33 Australian Government, Terrestrial ecoregions in Australia, ed. by Department of Sustainability E, Water, Populations and Communities: Interim Biogeographic Regionalisation for Australia (IBRA), Version 7, (2012). Available: https://www.environment.gov.au/land/nrs/ science/ibra/australias-ecoregions [3 April 2020].

34 Bailey RG, Description of the Ecoregions of the United States. US Department of Agriculture, Forest Service, Washington, DC (1980).

35 Bailey RG, Ecoregions, the Ecosystem Geography of the Oceans and Continents. Springer-Verlag, New York, NY (1998).

36 Snow NP and VerCauteren KC, Movement responses inform effectiveness and consequences of baiting wild pigs for population control. Crop Prot 124:104835 (2019).

37 McRae JE, Schlichting PE, Snow NP, Davis AJ, VerCauteren KC, Kilgo JC et al., Factors affecting bait site visitation: area of influence of baits. Wildl Soc Bull 44:362-371 (2019).

38 Halseth JM, Lavelle MJ, Snow NP and VerCauteren KC, Technical note: aging feral swine in the field. USDA/APHIS/WS/National Wildlife Research Center, Fort Collins, CO, p. 4 (2018).

39 Patton TG, Blamer SL and Horak KE, Detecting methemoglobinemia in animals with a drop of blood. PLoS One 11:e167942 (2016).

40 Ivan JS, Newkirk ES and CPW, Photo Warehouse: a custom database to facilitate archiving, identifying, summarizing and managing photo data collected from camera traps. Methods Ecol Evol 7:499-504 (2016).

41 Pollock KH, Nichols JD, Simons TR, Farnsworth GL, Bailey LL and Sauer JR, Large scale wildlife monitoring studies: statistical methods for design and analysis. Environmetrics 13:105-119 (2002).

42 Magnusson A, Skaug H, Nielsen A, Berg C, Kristensen K, Maechler M, van Bentham K, Bolker B, Brooks M and Brooks MM, Generalized Linear Mixed Models using Template Model Builder. In R Package Version 0.2.0 (2020). Available: http://cran.uni-muenster.de/web/packages/ glmmTMB/glmmTMB.pdf [16 April 2020].

43 Shapiro L, Eason C, Bunt C, Hix S, Aylett P and MacMorran D, Efficacy of encapsulated sodium nitrite as a new tool for feral pig management. J Pestic Sci 89:489-495 (2016).

44 Cowled BD, Gifford E, Smith M, Staples L and Lapidge SJ, Efficacy of manufactured PIGOUT ${ }^{\circledR}$ baits for localised control of feral pigs in the semi-arid Queensland rangelands. Wildl Res 33:427-437 (2006).

45 Poché RM, Poché D, Franckowiak G, Somers DJ, Briley LN, Tseveenjav B et al., Field evaluation of low-dose warfarin baits to control wild pigs (Sus scrofa) in north Texas. PLoS One 13:e0206070 (2018).

46 Beasley JC, Clontz LM, Rakowski A, Snow NP and VerCauteren KC, Evaluation of a warfarin bait for controlling invasive wild pigs (Sus scrofa). Pest Manage Sci in review.

47 Duguay JP, Davidson M, Lacour J and Vidrine T, Field evaluation of a commercial feeder to control wild pigs. J Southeast Assoc Fish Wildl Agencies 7:221-226 (2020).

48 Twigg LE, Lowe T, Martin G and Everett M, Feral pigs in north-western Australia: basic biology, bait consumption, and the efficacy of 1080 baits. Wildl Res 32:281-296 (2005).

49 Obrien $\mathrm{P}$, The toxicity of sodium monofluoroacetate (compound 1080 ) to captive feral pigs, Sus scrofa. Aust Wildl Res 15:163-170 (1988).

50 Mcllroy J, The sensitivity of feral pigs, Sus scrofa, to 1080 and its implications for poisoning campaigns. Wildl Res 10:139-148 (1983). 
51 Franckowiak GA, Torres-Poché Z, Poché DM and Poché RM, Movements of feral hogs in response to warfarin bait consumption, in Proceedings of the 28th Vertebrate Pest Conference, ed. by Woods DM. University of California, Davis, CA, pp. 100-108 (2018).

52 Poché RM, Davis N, Poché DM, Franckowiak GA, Tseveenjav B, Hartman DA et al., Development of a low-dose warfarin bait for controlling feral hogs. Crop Prot 120:134-140 (2019).

53 Diaz $M$, Interspecific patterns of seed selection among granivorous passerines: effects of seed size, seed nutritive value and bird morphology. Ibis 132:467-476 (1990).

54 Perkins AJ, Anderson G and Wilson JD, Seed food preferences of granivorous farmland passerines. Bird Study 54:46-53 (2007).
55 Best LB, Conservation tillage: ecological traps for nesting birds? Wildl Soc Bull 14:308-317 (1986).

56 Cunningham HM, Bradbury RB, Chaney $\mathrm{K}$ and Wilcox A, Effect of noninversion tillage on field usage by UK farmland birds in winter. Bird Study 52:173-179 (2005).

57 Cunningham HM, Chaney K, Bradbury RB and Wilcox A, Non-inversion tillage and farmland birds: a review with special reference to the UK and Europe. Ibis 146:192-202 (2004).

58 Snow NP and VerCauteren KC, Field evaluation of HOGGONE sodium nitrite toxicant bait for feral swine: EPA MRID 50784101, in Unpublished Report. NWRC Study No. QA-2612. National Wildlife Research Center, Fort Collins, CO, p. 272 (2019). 